\title{
RETRACTED ARTICLE: Research on the distal supervised learning model with tract variables
}

\author{
Shaobai Zhang $\cdot$ Ying Chen $\cdot$ Xiefeng Cheng
}

Received: 30 April 2012/ Accepted: 6 September 2012/Published online: 7 October 2012

(C) Springer-Verlag London Limited 2012

This article has been retracted at the request of the author, following concerns over the paper's integrity. 